\title{
COLUNI em Cena: a linguagem teatral no Ensino Médio
}

Eixo Temático: Ensino especializado e adaptado em Teatro

\section{RESUMO:}

Este texto é resultado de um trabalho sobre ensino de teatro que acontece há quatro anos no Colégio de Aplicação Coluni, da Universidade Federal de Viçosa (MG), com alunos do $1^{\circ}$ ano do Ensino Médio. O trabalho é realizado através do projeto "Coluni em Cena”, com o objetivo de desenvolver a linguagem teatral no Ensino Médio, em suas diferentes dimensões, artística, filosófica e social. O projeto, foi criado pela área de Arte e vem sendo desenvolvido de forma interdisciplinar com as áreas de Língua Portuguesa, História, Sociologia, Filosofia, Língua Espanhola, Literatura. O projeto possui várias atividades ao longo do ano (oficinas de improvisação teatral, cenário, figurino, leitura de texto dramático, etc), na busca de desenvolver o aprendizado sobre as técnicas teatrais. É acompanhado por um bolsista do PIBIC/EM (Programa Institucional de Bolsa de Iniciação Científica - Ensino Médio), o qual desenvolve, ao longo de um ano, uma pesquisa qualitativa que busca apreender, a partir da observação participante e da entrevista semiestruturada, o processo ensino/aprendizagem da linguagem teatral no contexto escolar. Ao longo desse período de desenvolvimento do projeto no colégio, pode ser ressaltado o papel social assumido pelo teatro, ao promover um trabalho de grupo e de constante diálogo entre os participantes; a compreensão das técnicas cênicas, sua importância para o entendimento da linguagem e, consequentemente, a mudança de percepção sobre o fazer teatral; e por fim, a construção de um processo educativo, rico e criativo que possibilita aos envolvidos, a ampliação do senso estético e artístico, além do desenvolvimento do gosto pelo teatro.

Palavras-chave: Ensino Médio. Linguagem teatral. Interdisciplinaridade. Projeto. Técnicas Teatrais.

\begin{abstract}
:
This text is the result of a work on drama teaching that has been taking place at the Federal high school Cap-COLUNI for four years with the students from the $1^{\text {st }}$ grade. The work is carried out through the project named "Coluni in scene", with the aim of developing the theatrical language in High School, in its different dimensions, artistic, philosophical and social. The project was created by the Art area and has been developed in an interdisciplinary way with the areas of Portuguese Language, History, Sociology, Philosophy, Spanish Language, and Literature. The project has several activities throughout the year (theatrical improvisation workshops, scenery, costumes, reading of dramatic text, etc.), in the search to develop the learning of theatrical techniques. It is accompanied by a PIBIC / EM porgram (Institutional Scholarship Program for Scientific Initiation - High School), which develops, during one year, a qualitative research that seeks to apprehend the teaching / learning process of theatrical language in the school context
\end{abstract}


from the participant observation and semi-structured interview. Throughout this period of project development in the college, the social role assumed by the theater can be emphasized as it promotes group work, constant dialogue among the participants, an understanding of the scenic techniques and their importance for the understanding of the theatrical language, and thus, the change of perception about the theatrical performance; finally, the project enables the construction of a rich and creative educational process that allows those involved, the widening of the aesthetic and artistic sense, as well as the development of the taste for the theater.

Key-words: High school. Theatrical language. Interdisciplinarity. Project. Theatrical Techniques.

Esse trabalho apresenta uma análise do ensino de Teatro na Escola, a partir da experiência que vem sendo realizada no Colégio de Aplicação Coluni, da Universidade Federal de Viçosa/MG, com alunos do $1^{\circ}$ ano do Ensino Médio. Desenvolver a linguagem teatral no Ensino Médio, como afirmam as Orientações Curriculares para o Ensino Médio (OCEM, 2006), permite ao aluno o envolvimento com elementos referentes à estrutura dramática, como o espaço, o texto dramatúrgico, personagem, espectador, etc, além de ser possível um diálogo de "outra natureza" em sala de aula e de novas possibilidades de conhecer a si e o outro. É através desse entendimento que o processo ensino/aprendizagem teatral, aqui apresentado, se baseia, acontecendo através do projeto "COLUNI em Cena”, que no ano de 2018 está em sua $4^{\mathrm{a}}$ edição. O trabalho é desenvolvido ao longo de todo o ano letivo, tendo como base a abordagem triangular do ensino de Arte, através de algumas ações: leitura e análise de textos dramáticos, de cenas teatrais, estudo da história do teatro, aulas de improvisação e interpretação teatrais, de figurino, cenário, oficinas de máscaras e bate-papo com pessoas envolvidas com teatro (atores e diretores teatrais). A proposta objetiva a busca pela compreensão do teatro em suas dimensões artística, filosófica, histórica, social e antropológica, de forma a contribuir para o desenvolvimento social e humano, através de uma atuação voltada para um processo de ação educacional artística organizada e de qualidade que possibilita a construção de um sujeito crítico. Criado pela área de Arte, para cumprir o conteúdo curricular de ensino de teatro, tem a parceria interdisciplinar de outras áreas, como História, Língua Portuguesa, Literatura, Língua Espanhola e Sociologia. Nesse caso, o ensino do teatro não está a disposição das outras disciplinas, a interdisciplinaridade, aqui, é entendida como ação pedagógica (FAZENDA, 2008) que busca circunscrever os conteúdos das disciplinas envolvidas no processo teatral, na busca da construção do conhecimento de forma 
mais harmônica e dinâmica. Ao final de um longo processo de estudos teórico/práticos e de um aprofundamento sobre o teatro, as 4 turmas com 40 alunos cada, são convidadas a adaptar, para 20 minutos, peças clássicas teatrais. Cada turma fica responsável por uma peça, escolhida pela equipe interdisciplinar, de forma a colocar em prática o conhecimento adquirido sobre os elementos teatrais. A finalização do processo acontece com a apresentação de suas montagens para toda a escola e convidados (familiares e amigos). Após esse momento, faz-se uma reflexão com os alunos, através de conversa para troca de opiniões e análise crítica sobre o que foi realizado, associada a um questionário com perguntas semiestruturadas, elaboradas pela equipe dos docentes, como forma de se ter um registro escrito para parte da análise do processo. Podemos concluir, ao longo desses anos, que os alunos têm construído uma aprendizagem sobre o teatro, havendo uma valorização deste enquanto processo e não simplesmente como mero produto, ao se ter um contato aprofundado com as técnicas teatrais. Através da análise dos questionários, os alunos demonstram que o gosto pelo teatro modifica, pois através do projeto é possível entrar em contato com a linguagem teatral, a qual, para muitos, era desconhecida. Alguns alunos dizem que fazer teatro não é brincadeira, não é fácil, é fruto de muito trabalho e pesquisa, o que demonstra uma modificação na forma de olhar a produção em arte e até mesmo a profissão artística, valorizando-as e desconstruindo a ideia de que arte é simplesmente pura inspiração. Uma questão bastante ressaltada pelos alunos é o processo de cooperação e de integração que o teatro possiblita, ao perceberem no fazer teatral a importância de um trabalho em grupo intenso e de um constante diálogo. Por fim, pode-se dizer que o ensino/aprendizagem teatral vem se revelando como uma forma interessante de promover a formação artística, intelectual, cultural e humana dos alunos.

\section{Referências bibliográficas:}

BRASIL. Orientações Curriculares para o Ensino Médio: linguagens, códigos e suas tecnologias. Brasília: Ministério da Educação, Secretaria de Educação Básica, 2006.

FAZENDA, I. O que é interdisciplinaridade? São Paulo: Cortez, 2008.

TRINDADE, Diamantino Fernandes. Interdisciplinaridade: Um novo olhar sobre as ciências. Editora Cortez. São Paulo. 2008 